\title{
Cover illustration of Primates vol. 63 (2022)
}

\author{
Masayuki Nakamichi ${ }^{1}$ Shinichiro Ichino ${ }^{2} \cdot$ Patrícia Izar $^{3} \cdot$ Aru Toyoda $^{4}$
}

Published online: 13 December 2021

(C) The Author(s), under exclusive licence to Japan Monkey Centre 2021

Cover illustration (Fig. 1): left: ring-tailed lemurs (Lemur catta), upper right: bearded capuchin monkeys (Sapajus libidinosus), lower right: stump-tailed macaques (Macaca arctoides). Photographs taken by Shinichiro Ichino, Luca Antonio Marino, and Aru Toyoda, respectively; all rights reserved.

In order to select the cover illustration for Primates in 2022, I asked Associate Editors, winners of the Primates 2021 Most-Cited Paper Award and Social Impact Award, and members of the Primate Society of Japan (PSJ) (Primates is a semi-official journal of PSJ) to submit candidate photographs. I sincerely thank everyone who offered photos of various primate species. Among the many fine photos offered, I finally selected three photos of different species, in consultation with the two Vice Editors-in-Chief. The following are explanatory notes provided by researchers who took the photographs and/or who have conducted observations on the primates for years. (Masayuki Nakamichi, Editor-in-Chief).

Ring-tailed lemurs (Fig. 2): an adult female carries three newborn infants, in Berenty Reserve, southern Madagascar. This is not a mother and triplets. Instead, the adult female is carrying her own infant and those of her two sisters. Moreover, she appears to nurse them (allonursing). The ring-tailed lemur is characterized by strict seasonal breeding, with gestation occurring during the dry season and lactation in the wet season. In Berenty, most females give birth annually around September. Troop members have a strong interest in newborn infants and frequently try to approach the mother and lick the infant. Infants sometimes move onto other group members through physical contacts, especially among close kin. In most cases the infant returns to its mother after a

\footnotetext{
$\triangle$ Masayuki Nakamichi

naka@hus.osaka-u.ac.jp

Osaka University, Suita, Japan

National Museum of Ethnology, Suita, Japan

3 University of Sao Paulo, São Paulo, Brazil

4 Chubu University, Kasugai, Japan
}

short time, but sometimes the transfer continues for more than a day. This adult female (ME-899401 9 ) belonged to troop C1 when the photo was taken in September 2006. Starting around 2004, there was tension among females in the troop, and this female and her sisters (ME-899499ㅇ and $M E-899402$ P) were evicted from the troop after some intense aggression by other females. Subsequently, the three sisters successfully rejoined the troop, and were dominant over other females by September 2006. The female and her sisters are likely to have shared strong bonds. In 1981, Dr. Naoki Koyama started observing individually identified

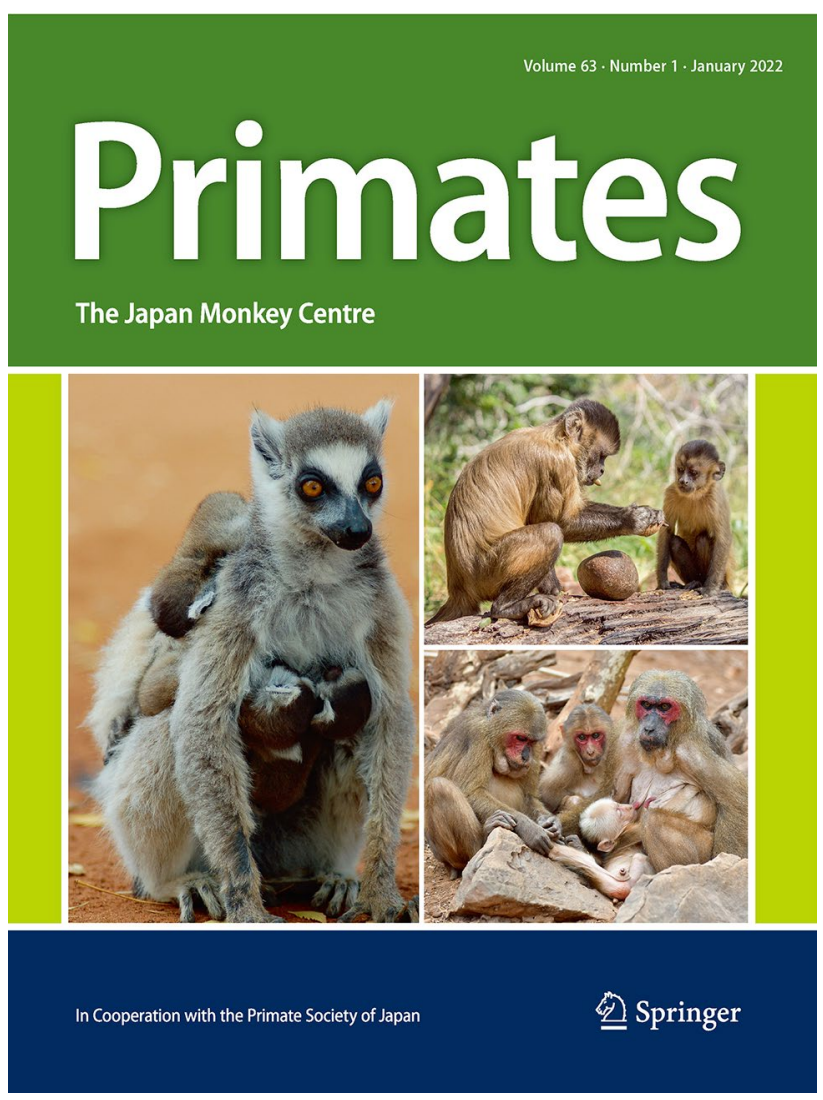

Fig. 1 Cover illustration of Primates, 2022 


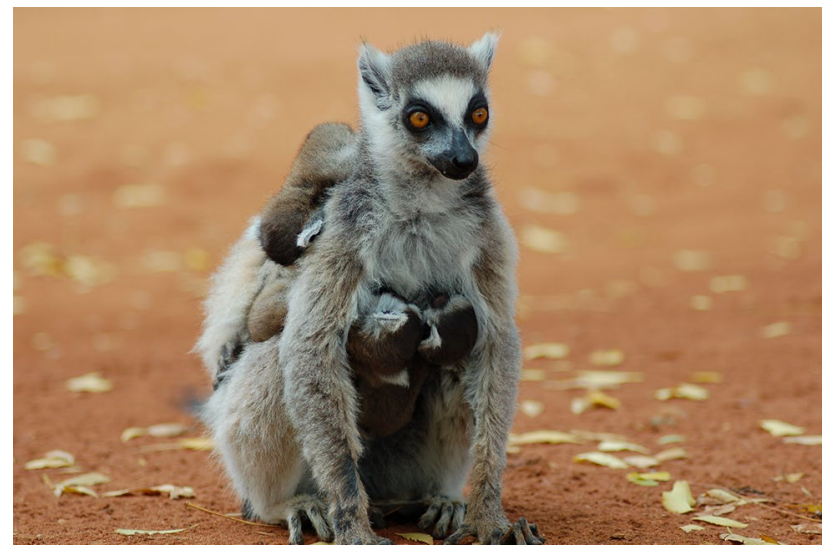

Fig. 2 Ring-tailed lemurs (Lemur catta). OShinichiro Ichino

ring-tailed lemurs in Berenty, and long-term studies by him and his coworkers have been going on since then. (Dr. Shinichiro Ichino).

Bearded capuchin monkeys (Fig. 3): an adult male ("Mansinho") with a palm nut kernel in his mouth; he has just cracked open the nut using a round-shaped, heavy stone as a hammer to pound the nut on a log anvil. The young male Coco is watching closely while Mansinho extracts remaining kernels from inside the shell. This photograph was taken by Luca Antonio Marino in October 2014 in Fazenda Boa Vista (FBV), in the state of Piauí, Brazil. At that time, Mansinho was a subordinate male in his group. He was previously the alpha male, but a change in status occurred in 2010 after a male takeover fight which resulted in him being severely injured and losing his left foot. In 2015 the group split, and since then he has been the alpha male of the smaller group. The bearded capuchins in FBV have been studied since 2003 by Dr. Patrícia Izar (University of São Paulo, Brazil), Dr. Elisabetta Visalberghi (ISTC, CNR, Italy), and Dr. Dorothy Fragaszy (University of Georgia, Athens, GA, USA), coordinators of the EthoCebus project. This long-term research revolutionized our understanding of conditions for tool use and traditional inheritance processes in nonhuman primates. Challenging the view that capuchins have no understanding of properties of objects, naturalistic observation and field experiments demonstrated that capuchins in FBV perceive the affordances of tool materials and tasks, such as weight and friability of stones and resistance of nuts, and are capable of at least short-term planning when selecting stones and adjusting their body movements and force for nuts of different resistance. These skills develop through a long process (ca. 5 years) of individual practice, socially influenced by the activity and artifacts of skilled group members that attract sustained attention of unskilled youngsters. Unfortunately, these amazing monkeys and their traditions along with the traditions of the local human communities that have coexisted for millennia are now at risk due to expanding,

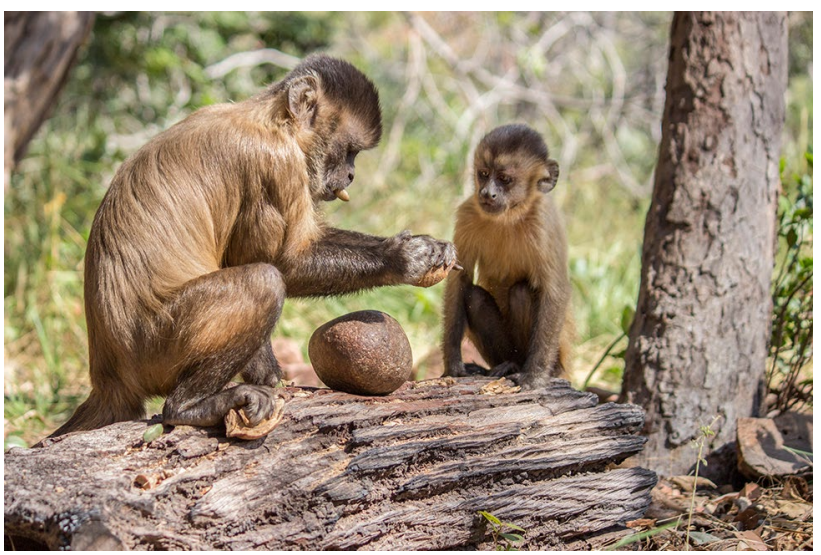

Fig. 3 Bearded capuchin monkeys (Sapajus libidinosus). OLuca Antonio Marino

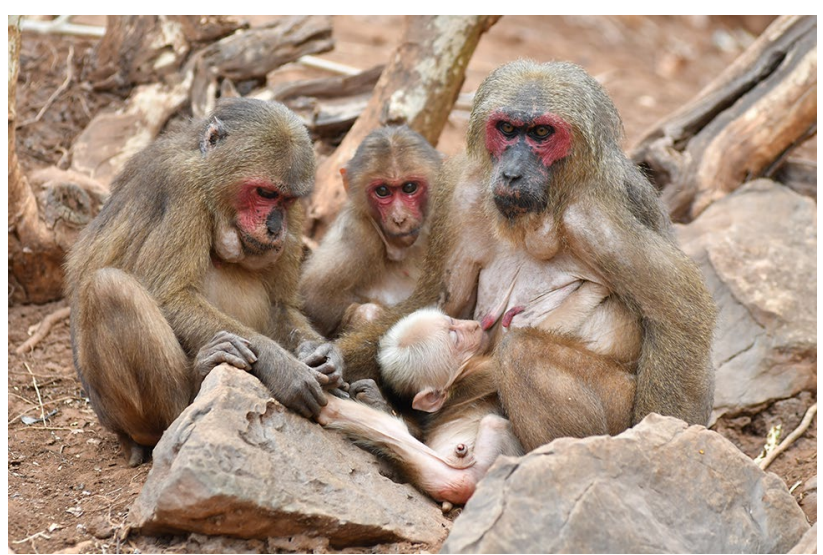

Fig. 4 Stump-tailed macaques (Macaca arctoides). @Aru Toyoda

intensive agriculture in the region. It is our duty as primatologists to raise awareness about the impact of human activities on the environment and fight for the survival of other species. (Dr. Patrícia Izar).

Stump-tailed macaques (Fig. 4): the stump-tailed macaque (or bear macaque) is the most distinctive species in genus Macaca in terms of reproductive anatomy and reproductive behaviors. This species is widely distributed in continental Southeast Asia including northeastern India, southern China, Myanmar, Laos, Thailand, Vietnam, Cambodia, and the northwest tip of West Malaysia on the Malay Peninsula. As the Japanese name implies (benigao in Japanese means rosy-faced in English), both males and females have red faces. The color of the dorsal pelage is usually reddishbrown, but some individuals in southern populations have a blackish pelage. The blackish population used to be classified as a different subspecies ( $M$. arctoides melanota). Unusually for this genus, infants are born with a completely different pelage color from adults; it is whitish or pale-golden, turning darker as the infant matures. Whitish infants play an 
important role as a catalyst for various social interactions. Adults show interest in white infants and frequently touch their genitals. This behavior, described as "Touch Baby's Genitals," can trigger social interactions with the mother as she carries the infant or relieve tension between adults in an aggressive context. These are examples of "agonistic buffering." The photograph shows a family of wild stump-tailed macaques - a mother feeding her infant and older siblings welcoming their new brother. An older daughter sitting next to her mother touches her younger brother's genitals. As the mother always pays attention to her infant, the young daughter may be looking for opportunities to interact with her mother through touching the infant. The photograph was taken in October 2020 at Khao Krapuk Khao Taomor
Non-hunting Area, Phetchaburi province, Thailand. There were known to be 22 individuals in this population when it was first studied in 1988. Currently, it has at least 391 individuals, divided into five groups, recorded by A. Toyoda in 2017. This population has been studied since 2015 by A. Toyoda, under the supervision of Prof. Dr. Tamaki Maruhashi. (Dr. Aru Toyoda).

Publisher's Note Springer Nature remains neutral with regard to jurisdictional claims in published maps and institutional affiliations. 